\title{
The Influence of Organizational Culture on Police Corruption in Libya
}

\author{
${ }^{1}$ Omer M. Othman Domoro, ${ }^{2}$ Syed Omar Syed Agil \\ ${ }^{1}$ (Graduate School of Business, Tun Abdul Razak University, Malaysia). \\ ${ }^{2}$ ( Razak School of Government, Tun Abdul Razak University, Malaysia).
}

\begin{abstract}
There are many factors influencing police corruption. Some of these factors are considered to be organizational in nature while others are more specifically related to the nature and context of police work itself. The majority of these factors influence the relationship between the police and the society and causes police corruption. For example, organizational culture is enormously important in determining the level of police corruption. This study aims to determine the influence of organizational culture on corruption among members of the Libyan police force. A total of 348 Libyan police members participated in the study. Regression and correlational analyses were performed as a methodology to this study. The study shows that organizational culture has an inverse negative relationship with police corruption. The study results have practical implications for policy makers in the Libyan National Police to increase the employee management loyalty to the organization and have successful criterion could prevent or reduce corruption. Thus, effort should be made to foster a better management, organization glue and criteria of success among the police to reduce the tendency for corruption.
\end{abstract}

Keywords: corruption- Libya - organizational culture-police force-police organization.

\section{Introduction}

\section{Police Corruption}

Police corruption is a real problem in many countries in the world, where the police are perceived as one of the most corrupt organizations in the states [1]. Despite the common public perception that police corruption is widespread; addressing it is a sensitive issue for governments because of the lack of easy solution to the problem [2].

In the past the prevailing interpretation of police corruption depends on the individual characteristics of police officers. It was believed that police officers were involved in corruption because of low moral values. When the corrupt behavior is known to the public, the managers were quick to consider this category as rotten apples and treatment of this category is to reprimand them, and reproach them on this behavior. Sanja's interpretation of police corruption is based on a combination of factors including lack of morals of individual police, other factors related to police organization, leadership of the police, breach of rules, drugs and internal control systems. Police corruption is an act or omission, a promise of action or omission, or an attempted action or omission, committed by a police officer or a group of police officers, described by the police officer's abuse of the official position, motivated in important part by the achievement of private gain [3].

The rotten apple theory became the easy way to explain police corruption, especially by the administration, it is a simplistic explanation that allows the organization and senior management to blame the individual behavior, rather than addressing the structural factors. The focus is on the behavior of individuals only, and regulatory issues can be ignored or underestimated. The bad apple theory justifies police corruption as an ethical failure. However, it is not a sufficient justification in terms of the reality of organizational culture and professional police work in contribution to development and it is necessary to examine, within the structure and culture of police work and police organization that is more difficult to deal with than the ethical flaws [4].

Some researchers argue that all efforts that focus on tightening laws, supervision and transparency are not sufficient to address the problem of corruption, which requires the establishment of a system of moral and culture for employees in order to promote these values within the organizations. Furthermore, encouraging the inclusion of moral values in the training programs will reduce the chances of corrupt behaviors [e. g. 5, 6, 7, 8, $9,10]$.

\section{Organizational Culture}

Most previous studies on the relationship between organizational culture and corruption in the police tried to focus on the role of culture in general to influence the behavior of individuals within the police organization and its implications. Culture in a police organization can have a positive or negative impact on the way in which police staff carry out their functions from the point of view of most of these researchers. Understanding the effect of culture on the individual behaviors on police organization can be used to improve 
individual productivity within the police organization. It can also be used to make radical changes in the prevailing culture in the police to avoid the negative effects of culture such as corruption and low performance of the organization and its working groups.

Corruption inside the Indian police organization is not a new phenomenon and exists in many forms and has reached an alarming stage where some practices are not even considered deviant. Pervasive corruption is an expression of the culture that has its roots in the British Raj. Among other factors, culture determines the level of honesty and integrity of the members of the police organization, the role and function of any police department is adversely affected if the prevailing norms and traditional ways of doing things encourage corrupt practices. Verma said that to control corruption in a police organization and to reform the system is to make changes in the way things are being done [11].

Police corruption cannot exist without at least implicit or implied acceptance by the police agency. The cultural influence on police misconduct and deviant behavior is found in the degree to which such misbehavior is tolerated or even encouraged by the organization. Unfortunately, acts of corruption, brutality, and malfeasance that go unchallenged can become tolerable, unobjectionable and common. The action or inaction of managers and supervisors is critical in this regard in that they can easily create an atmosphere of eroding standards eventually leading to significant acts of corruption by their subordinates [12].

Based on earlier study examined the influence of police organizational culture on officers' perception of integrity in the Turkish National Police, the officers' perception of police organizational culture negatively influenced their perception of integrity and the influence of organizational culture on officers' perceptions of integrity is limited to the minor or noble cause rule breakings. Administrators and mid-level managers should be aware of the negative role played by the police organizational culture and develop a positive organizational culture as an important step in developing an effective strategy to enhance police integrity [13].

Based on the review of the relevant literature discussed above the study hypothesis will be:-

HO There is no relationship between organizational culture and corruption in the Libyan police force.

H1 There is a significant relationship between organizational culture and corruption in the Libyan police force.

\section{Design and Sampling}

\section{Methodology}

This study utilizes quantitative approach using questionnaire survey in investigating the relationship between the variables of interest in the study. Stratified random sampling was used where questionnaires were distributed to the sample of Libyan police. A total of 384 members of the Libyan police were chosen as sample size for the study. SPSS was used in this study to analyze quantitative data collected from the responses using questionnaire surveys.

\section{Measurement \\ Dependent Variables}

The dependent variable in this study is police corruption. A total of 36 items were used to measure the dependent variable adopted from [14]. These sets of instruments used to measure the dependent variable have shown satisfactory reliability and validity of the scales applied. Some of the items asked on the questionnaire are "It is absolutely acceptable for a police officer to use his position in order to achieve some personal gain though the way to achieve the gain is illegal" and "A police officer can differentiate on his own what is a "sign of appreciation» and what is bribery." The second statements used to measure police corruption were: "It is indispensable to adopt a new rulebook on additional payment for overtime police work". "There is strict application of control over police officers and application of sanctions for misuse of duty". All these items were ranked on a five-point Likert scale of ( $1=$ strongly disagree; $5=$ strongly agree $)$ to measure respondents aspects of corruption perception in the Libyan police force.

\section{Independent Variables}

Organizational culture is the independent variables in the study. A total of 24 items were included in the questionnaire to measure different aspects of the police culture in their organization. Organizational culture is measured through the organizational culture assessment instrument (OCAI) developed by [15] which assesses six key dimensions of organizational culture are dominant characteristics, organizational leadership, management of employees, organizational glue, strategic emphases and criteria of success. The reliability in the context of the OCAI refers to the extent to which the instrument measures culture types consistently [16].

This part contains of 6 dimensions that that respondents are asked to consider in order to rate their organization. Every question has four choices. Response descriptions against items were given on a five-point Likert-type scale ( $1=$ strongly disagree; $5=$ strongly agree $)$ among the four choices depending on the extents to which each choice describes their organization.

This mechanism has been found to be both useful and accurate in analyzing important aspects of an organization's underlying culture. It has been used in more than a thousand organizations and it has been found 
to predict organizational performance. Examples of the items include statements like "My organization is a very personal place. It is like an extended family. Police members seem to share a lot of them" and "The management style in the police organization is characterized by teamwork, consensus, and participation".

\section{Regression Analysis}

\section{Results}

The descriptive table below shows the mean and standard deviation (M (SD)) of variables in the study. The organizational culture score highest mean which is, $4.17(0.221)$. The dependent variable, police corruption has mean score of 3.67(0.180). The respondents were 384 in total.

Table 2Descriptive statistics

\begin{tabular}{llll}
\hline & Mean & Std. Deviation & $\mathrm{N}$ \\
\hline Police corruption & 3.6682 & .17961 & 384 \\
Organizational culture 4.1729 & .22173 & 384 \\
\hline
\end{tabular}

\section{Correlational Analyses}

The correlational analysis in the table below was between organizational culture and corruption in the Libyan police force. From the table, the researcher can detect a significant correlation that has been reported in testing research hypotheses. The correlations are shown as colored values. The correlational analysis in the table below shows that organizational culture (independent variables) has a significant relationship with the police corruption (dependent variable) in the study. The results of the correlations can be reported as;

Police corruption and Organizational culture, $r=-0.117, p<0.05$,

This result indicated that police corruption has an inverse relationship with the organizational culture. A negative relationship between organizational culture and police corruption has been identified based on testing the research hypothesis

\begin{tabular}{l|l|l|l}
\hline \multirow{3}{*}{ Pearson Correlation } & & Police corruption & Organizational culture \\
\cline { 2 - 4 } & Police corruption & 1.000 & -.117 \\
\cline { 2 - 4 } & Organizational culture & -.117 & 1.000 \\
\hline \multirow{2}{*}{ Sig. (1-tailed) } & Police corruption &. & .011 \\
\cline { 2 - 4 } & Organizational culture & .011 &. \\
\hline
\end{tabular}

$$
\mathrm{N}=384
$$

Table 4 Descriptive Statistics of Police Corruption and Organizational Culture's dimension

\begin{tabular}{llll} 
& Mean & Std. Deviation & $\mathrm{N}$ \\
\hline Corruption & 3.6682 & .17961 & 384 \\
Dominant Characteristics & 4.2344 & .35459 & 384 \\
Organizational Leadership & 4.2728 & .32110 & 384 \\
Management of Employees & 4.1589 & .36868 & 384 \\
Organization Glue & 4.1191 & .39699 & 384 \\
Strategic Emphasis & 4.1035 & .42582 & 384 \\
Criteria of Success & 4.2051 & .35091 & 384 \\
\hline
\end{tabular}

The descriptive table above shows the mean and standard deviation $(\mathrm{M}( \pm \mathrm{SD}))$ of all dimensions in the organizational culture and corruption. There were six dimensions in the organizational culture. The highest mean score in the dimensions was organizational leadership $4.27( \pm 0.321)$, followed by dominant characteristics $4.23( \pm 0.355)$, criteria of success $4.21( \pm 0.351)$, management employees $4.16( \pm 0.369)$, organizational glue $4.12( \pm 0.397)$ and the lowest mean score was the strategic emphasis $4.10( \pm 0.426)$. The dependent variable police corruption has mean score of $3.67( \pm 0.180)$. The respondents were 384 in total. 
Table 5 Correlations between Police Corruption and Organizational Culture dimensions

\begin{tabular}{|c|c|c|c|c|c|c|c|c|}
\hline & & Corr & $\begin{array}{l}\text { Dom } \\
\text { Charac }\end{array}$ & $\begin{array}{l}\text { Org. } \\
\text { Lead. }\end{array}$ & $\begin{array}{l}\text { Mgt. } \\
\text { of.Employ. }\end{array}$ & $\begin{array}{l}\text { Org. } \\
\text { Glue }\end{array}$ & Stra.Empha & $\begin{array}{l}\text { Cri. } \\
\text { of.Succ }\end{array}$ \\
\hline Pearson & Corruption & 1.000 & .051 & -.081 & -.171 & -.107 & -.036 & -.153 \\
\hline \multirow[t]{6}{*}{ Correlation } & Dom Charac. & .051 & 1.000 & -.027 & .010 & .148 & .611 & .026 \\
\hline & Org. Lead. & -.081 & -.027 & 1.000 & .115 & .181 & .014 & .303 \\
\hline & Mgt.of.Employ. & -.171 & .010 & .115 & 1.000 & .383 & .291 & .663 \\
\hline & Org.Glue & -.107 & .148 & .181 & .383 & 1.000 & .203 & .567 \\
\hline & Stra.Empha. & -.036 & .611 & .014 & .291 & .203 & 1.000 & .172 \\
\hline & Cri.of.Succ. & -.153 & .026 & .303 & .663 & .567 & .172 & 1.000 \\
\hline \multirow{7}{*}{$\begin{array}{l}\text { Sig. } \\
\text { (1-tailed) }\end{array}$} & Corruption & . & .158 & .056 & .000 & .018 & .238 & .001 \\
\hline & Dom Charac. & .158 & . & .299 & .420 & .002 & .000 & .307 \\
\hline & Org. Lead. & .056 & .299 & . & .012 & .000 & .394 & .000 \\
\hline & Mgt.of.Employ & .000 & .420 & .012 & . & .000 & .000 & .000 \\
\hline & Org.Glue & .018 & .002 & .000 & .000 & . & .000 & .000 \\
\hline & Stra.Empha. & .238 & .000 & .394 & .000 & .000 & . & .000 \\
\hline & Cri.of.Succ. & .001 & .307 & .000 & .000 & .000 & .000 & . \\
\hline
\end{tabular}

Corr=Corruption, Dom.Charac=Dominant of Characteristics, Mgt.of.Employ=Management of Employess, Org. Glue $=$ Organization Glue, Stra.Empha=Strategic Emphases, Cri.of.Succ $=$ Criteria of Success. $p<0.05$.

The above table depicts the correlations between all organizational culture's dimensions. From the table, the researcher can detect which organizational culture dimensions show a significant correlation with the police corruption. The correlations are shown as colored values. By neglecting the significant level of $p<0.05$, the maximum correlation is recorded by management of employees $(17.1 \%)$ followed by criteria of success $(15.3 \%)$, organization glue $(10.7 \%)$, organizational leadership $(8 \%)$ and dominant characteristics $(5 \%)$. The lowest correlation is recorded by strategic emphases (4\%). In other words, the first five dimensions of organizational culture mentioned above recorded negative relationships with police corruption based on the correlations analysis. The positive relationship recorded only with last dimensions which is strategic emphases. The researcher can determine that the dependent variable police corruption was significantly correlated at $\mathrm{p}<$ 0.05 with three of the dimensions. The results of the correlations can be reported as;

Police corruption and Management of Employees, $r=-0.171, p<0.05$,

Police corruption and Organization Glue, $r=-0.107, \mathrm{p}<0.05$, and

Police corruption and Criteria of Success, $r=-0.153, p<0.05$

From the results above police corruption has negative relationships with all significant correlated dimensions. They have an inverse relationship which was negative correlation with police corruption. The highest correlation between the police corruption and organizational culture dimensions was the management of employees, $r=-0.171$. However, the correlation is low. The closer the ' $r$ ' value to 1 , the stronger the relationship. The researcher can assume that, the higher the police corruption, the lower the management of employees of the Libya police force.

Table 6 Model Summary

\begin{tabular}{lllll}
\hline Model & $\mathrm{R}$ & $\mathrm{R}^{2}$ & $\begin{array}{l}\text { Adjusted } \mathrm{R} \\
\text { Square }\end{array}$ & $\begin{array}{l}\text { Std. Error of the } \\
\text { Estimate }\end{array}$ \\
\hline 1 & $.197 \mathrm{a}$ & .039 & .023 & .17749 \\
\hline
\end{tabular}

The next table is the Model Summary. The $\mathrm{R}^{2}$ value in the Model Summary table shows the amount of variance in the dependent variable (Police corruption) that can be explained by the organizational culture dimensions (dominant characteristics, organizational leadership, management of employees, organization glue, strategic emphasis and criteria of success).

The $\mathrm{R}$ value (0.197) indicates the multiple coefficients between all the entered organizational culture dimensions (dominant characteristics, organizational leadership, management of employees, organization glue, strategic emphasis and criteria of success) and the dependent variable (police corruption). The police corruption 
was correlated with the dominant characteristics, organizational leadership, management of employees, organization glue, strategic emphasis and criteria of success. The $\mathrm{R}$ value indicated that the closer the value to 1 , the stronger the relationship. These findings shows that the $R=0.197$ has a low relationship and positively correlated with the combined dimensions.

Table 7 Anova b

\begin{tabular}{lllllll}
\hline Model & Sum of Squares & $\mathrm{df}$ & Mean Square & $\mathrm{F}$ & Sig. \\
\hline 1 & Regression & .479 & 6 & .080 & 2.535 & $.020 \mathrm{a}$ \\
& Residual & 11.877 & 377 & .032 & & \\
\cline { 3 - 6 } & Total & 12.356 & 383 & & & \\
\hline
\end{tabular}

a. Predictors: (Constant), Cri.of.Succ, Dom.Charac, Org.Lead., Org.Glue, Stra.Empha, Mgt.of.Employ

b. Dependent Variable: Police Corruption

The ANOVA table above shows that Sig. ( $\mathrm{p}$ value $)=0.020$. As $\mathrm{p}<0.05$, the predictions are significantly better than would be expected. It is reported as; $\mathrm{F}(6,377)=2.535 ; \mathrm{p}<0.05$. This implies that the predictor dimensions jointly and significantly predict the dependent variable (corruption). The ANOVA table further reveals that the predictor dimensions when combined together accounted $\left(\mathrm{R}^{2}=0.039\right) 4 \%$ of the total variance observed in performance $(\mathrm{R}=0.197, \mathrm{~F}=2.535$ and $\mathrm{p}<0.05)$.

Table 8 Coefficients table between all the Organizational Culture dimensions a

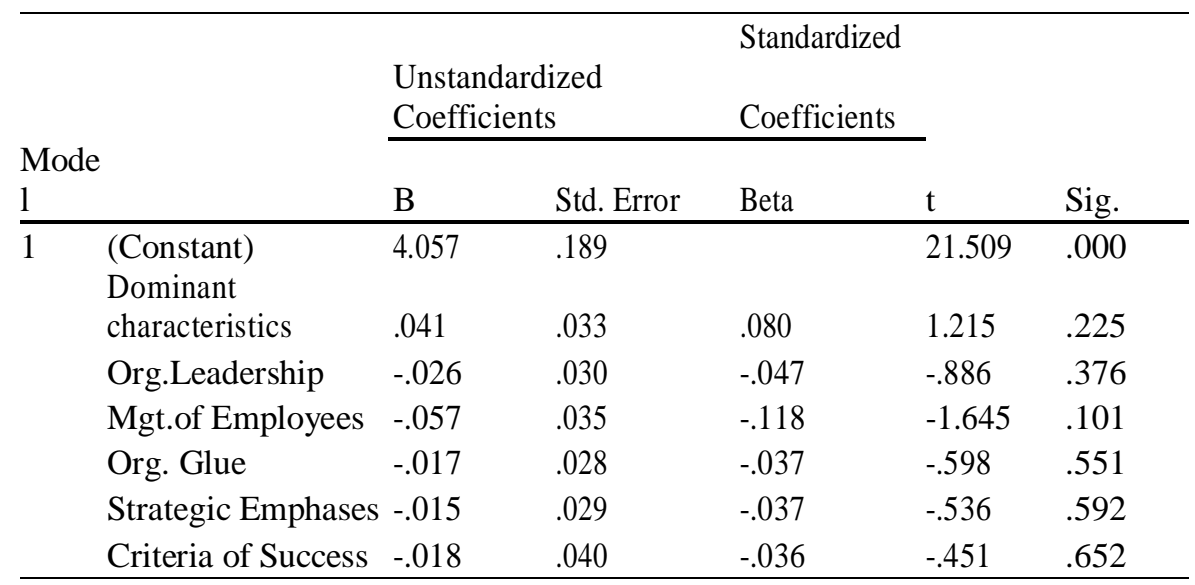

a. Dependent Variable: Police

Corruption

The next part of the output is Coefficients table showing which dimensions are significant with the dependent variable (police corruption).

The Unstandardized Coefficients B column represents coefficients of organizational culture dimensions (dominant characteristics, organizational leadership, management of employees, organization glue, strategic emphasis and criteria of success) in the regression equation.

Police corruption $=4.057+(0.041)$ Dominant characteristics $+(-0.026)$ Organizational leadership $+(-$ $0.057)$ Management of employees $+(-0.017)$ Organization glue $+(-0.015)$ Strategic emphases $+(-0.018)$ Criteria of success.

The standardized Beta Coefficient column shows the contribution that an individual dimension makes to the model. The beta weight is the average amount of dependent variable increases when the independent variable increases by one standard deviation (all other dimensions were held constant). The largest influence on police corruption was management of employees $(\beta=-0.118)$ which has been reported in the Standardized Beta Coefficient column. T-test was also performed to test the two-tailed hypothesis that the beta value is significantly higher or lower than zero. This enables the researcher to see which predictors were significant. From the table, none of organizational culture dimensions were a significant predictor to the police corruption. However, based on the standardized Beta coefficient, in term of predicting police corruption, management of employees contributed to the highest police corruption, which recorded $12 \%(\mathrm{~B}=-0.057, \mathrm{t}=-1.645, \mathrm{p}>0.05)$, followed by dominant characteristics, $8 \%(B=0.041, t=1.215, p>0.05)$ and organizational leadership, $5 \%(B=$ $-0.026, t=-0.886, p>0.05)$. The lowest contribution were the organization glue $(B=-0.017, t=-0.598, p>0.05)$, strategic emphases $(B=-0.015, t=-0.536, p>0.05)$ and criteria of success $(B=-0.018, t=-0.451, p>0.05)$ each of them contributed $4 \%$ to police corruption. 


\section{Discussion And Conclusions}

\section{Discussion}

In this study, the research question was answered. Findings from the research question revealed a significant relationship exists among organizational culture $(\mathrm{r}=-0.117)$, and police corruption. The study shows that organizational culture had an inverse negative relationship with police corruption. The relationships are moderately high and significant as the significant level was set at 0.05 . The independent variable organizational culture $(B=-0.164, t=-4.208, p<0.05)$, had a significant relative contribution to the police corruption based on regression analysis. Estimated contribution for the organizational culture to police corruption was (20\%).

Regression analysis was performed on the independent variable dimensions to further confirm the research question findings. Three out of six dimensions in organizational culture had significant inverse relationships with police corruption; management of employees $(r=-0.171)$, organization glue $(r=-0.107)$ and criteria of success $(r=-0.153)$. However, the entire dimensions did not significantly contribute to police corruption. By neglecting the significant level at $\mathrm{p}<0.05$ based on the standardized Beta coefficient, in term of predicting police corruption, management of employees contributed to the highest corruption and report 12\% (B $=-0.057, \mathrm{t}=-1.645)$, followed by dominant characteristics, $8 \%(\mathrm{~B}=0.041, \mathrm{t}=1.215)$ and organizational leadership, $5 \%(\mathrm{~B}=-0.026, \mathrm{t}=-0.886)$. The lowest contribution were the organization glue $(\mathrm{B}=-0.017, \mathrm{t}=-$ $0.598)$, strategic emphases $(B=-0.015, t=-0.536)$ and criteria of success $(B=-0.018, t=-0.451)$ each of them contributes $4 \%$ to the police corruption. The $\mathrm{R}^{2}=0.039(4 \%)$ was the amount of variance in the dependent variable (Police Corruption) that can be explained by the organizational culture dimensions when combined together.

\section{Conclusions}

The results of the statistical analysis supported the alternative research hypothesis. The findings showed that the organizational culture of the Libyan police force negatively influences their perception of corruption. These findings are consistent with the earlier study conducted by [13] who discussed the influence of police organizational culture on perception of police integrity including corruption, revealed a negative relationship between officers' perception of organizational culture and their perception of integrity. In this study, results of the organizational culture dimensions indicated that only management of employees, organization glue and criteria of success had a significant inverse relationship with the police corruption. These finding has some implications. With a poor management of employees, organization glue and criteria of success, the police force might tend in the mire of corruption. The efforts to increase employees management, loyalty to the organization and has successful criterion could prevent or reduce corruption. Being just dominant in characteristics, organizational leadership and strategic emphases do not contribute to police corruption based on the insignificant relationship. Thus, efforts should be made to foster a better management, organization glue and criteria of success among the police to ensure zero corruption.

\section{References}

[1] Quah, Jon S T., Preventing police corruption in Singapore: the role of recruitment, training and socialization, The Asia Pacific Journal of Administration, Vol. 28, 2006, 59-75.

[2] Neild, Rachel, U S A I D program brief: anticorruption and police integrity, United States Agency for International Development, 2007, 1-17.

[3] Ivkovic, Sanja Kutnjak, Controlling police corruption (Oxford University Press, 2005).

[4] Loree, Don, Corruption in Policing: Causes and Consequences A Review of the Literature, Royal Canadian Mounted Police, 2006, pp. 1-31.

[5] Zekos, G. I., Ethics versus corruption in globalization, Journal of Management Development, Vol. 23, 2004, $631-647$.

[6] Alatas, Syed Hussein, "Promoting business ethics in Malaysia." Good governance for development: private sector perspectives Malaysian institute of integrity: Including proceedings of the National Seminar for Private Sector on the National Plan "Reinventing the future through good governance", 2006, pp.165-173. Kuala Lumpur: Malaysian Institute of integrity.

[7] Gbadamosi, G and Joubert, P., Money ethic, moral conduct and work related attitudes: field study from the public sector in Swaziland, Journal of Management Development, Vol. 24, 2005, 754-763.

[8] Adebayo, D.O., Ethical attitudes and prosocial behavior in the Nigeria police, moderator effects of perceived organizational support and public recognition, Policing: An International Journal of Police Strategies \& Management, Vol. 28, 2005, 684-705.

[9] Small, M. W., Management development: developing ethical corporate culture in three organizations, Journal of Management Development, Vol. 25, 2006, 588-600.

[10] Abdel- Latif, Assar Fakhri, The impact of professional ethics in reducing the opportunities for corruption in government jobs, Journal of Human Sciences, Vol. 24, 2006, 1-15.

[11] Verma, A., Cultural roots of police corruption in India, Policing: An International Journal of Police Strategies \& Management, Vol. 22, 1999, 264-279.

[12] Swope, Ross E., Ethics, integrity and the police culture, International Criminal Police Review, 2004, 1-7.

[13] Kucukuysal B., Determinants of Turkish police officers' perception of integrity: Impact of organizational culture, doctoral diss., University of Central Florida, Ph.D, 2008.

[14] Maljevic, Almir.,Datzer, Drake., Muratbegovic, Elmedin and Budimlic, Muhamed, Overtly about police and corruption, Association of criminalists in Bosnia and Herzegovina, 2006, pp. 1-265.

[15] Cameron, K., \& Quinn, R., Diagnosing and changing organizational culture, (USA: Addison-Wesley Publishing Company, Inc, 1999).

[16] Cameron, Kim S. and Quinn, Robert, Diagnosing and changing organizational culture: based on the competing values framework. Revised ed. (San Francisco: John Wiley \& Sons, Inc, 2006). 